\title{
VOC concentration in Taiwan's household drinking water
}

\author{
H.-W. Kuo ${ }^{\mathrm{a}, *}$, T.-F. Chiang ${ }^{\mathrm{a}}$, I.-I. Lo ${ }^{\mathrm{a}}$, J.-S. Lai ${ }^{\mathrm{a}}$, C.-C. Chan ${ }^{\mathrm{b}}$, J.-D. Wang ${ }^{\mathrm{b}}$ \\ ${ }^{a}$ Institute of Environmental Health, China Medical College, Taichung, Taiwan \\ ${ }^{b}$ Institute of Occupational Medicine and Industrial Hygiene, College of Public Health, National Taiwan University, \\ Taipei, Taiwan
}

Received 7 June 1997; accepted 9 September 1997

\begin{abstract}
The objective of this study is to analyze volatile organic compound (VOC) concentrations in Taiwan's drinking water supply. Focusing on Taiwan's three major metropolitan areas - Taipei, Taichung and Kaohsiung (in the north, middle and south, respectively) - 171 samples were taken from tap water and 68 from boiled water. Tests showed VOC concentrations were highest in Kaohsiung. This is due to different water sources and methods of treatment. Except for bromoform, trihalomethane (THM) concentrations were highest. Detection rates of toluene and 1,2-dichloroethane were slightly higher than other VOC compounds. VOC concentrations decreased significantly after water was boiled. THMs had a removal rate from $61 \%$ to $82 \%$. The authors conclude that the three metropolitan areas contain significantly different levels of VOCs and that boiling can significantly reduce the presence of VOCs. Other sources of pollution that contaminate drinking water such as industrial plants and gas stations must be further investigated. (C) 1997 Elsevier Science B.V.
\end{abstract}

Keywords: VOC concentration; Houschold drinking watcr

\section{Introduction}

Due to Taiwan's recent industrial development, water pollution has become a major concern.

\footnotetext{
*Corresponding author: No. 91, Hsueh-Shin Road, Taichung, Taiwan. Tel.: + 8864 2054076; fax: + 88642019901 ; e-mail: wukuo@cmce.cmc.edu.tw
}

Industrial pollutants from factories have been a continuing source of contamination in its rivers. The problem demands attention because Taiwan's primary sources of water are rivers. The high concentration of petrochemical plants in southern Taiwan has led to relatively high levels of volatile organic compounds (VOCs) such as benzene, toluene and halogenated aromatics (Kuo et al., 1996). Contaminated rivers have prompted the 
Taiwan Water Supply Corporation (1995) to add higher levels of chlorine to its water supply. This move has had a large affect on residents in Taiwan since roughly $90 \%$ of all households use tap water as their primary source of water. A previous study (Chiang, 1995) has shown tap water in southern Taiwan to have higher levels of total trihalomethane (THM) than any other area on the island. Larsen et al. (1983) found that pipes transporting drinking water can produce tetrachloroethylene (PCE) from the inner vinyl lining of certain asbestos-cement water distribution pipes. Because there are many sources of chemical contamination of drinking water in Taiwan, it is imperative that a thorough study be performed to monitor the quality of its tap water. Unfortunately, the Taiwan Water Supply Corporation regularly checks THM levels only in purification plants and not in households. Morris et al. (1992) used meta-analysis to find a positive association between consumption of chlorination by-products in drinking water and bladder and rectal cancer in humans. Attias et al. (1995) studied cancer and its link to trihalomethanes in drinking water. He found trihalomethane levels from 8.1 to $13.6 \mu \mathrm{g} / 1$ in ground water and from 52.8 to $168 \mu \mathrm{g} / \mathrm{l}$ in surface water. Based on data from various tumors in animals, he concluded the carcinogenic risk estimates for different THM concentration vary from $2.7 \times 10^{-7}$ to $4.6 \times 10^{-6}$ per $\mu \mathrm{g} / 1$ in relation to different carcinogenic substances.

The current study is significant because Taiwan's current overall leading cause of death is malignant cancer. This may be due to lifestyle habits or environmental pollution. However, because of the difficulty of measuring levels of chemical substances in drinking water, there is no data in Taiwan regarding the relationship between water quality and cancer mortality rates. The current study was done so a database could be established for the government to work toward a goal of one day allowing the people of Taiwan to directly drink the tap water without boiling it first.

\section{Experimental methods}

\subsection{Study area}

This study was performed in the three major metropolitan areas in Taiwan - Taipei, Taichung and Kaohsiung. The total population of these three areas constitutes nearly $25 \%$ of Taiwan's total population. The water samples were taken randomly from each city district in each of the three cities (Taipei, 11 districts; Taichung, 8 districts; and Kaohsiung, 10 districts). A total of 171 samples were taken.

\subsection{Chemical}

Twenty-four purgable VOCs were obtained from Supleco (Supelco, Bellefonte, PA, USA). Internal standards of bromochloromethane, 1,4difluorobenzene and chlorobenzene- $d_{5}$ were purchased from Supelco. 1,2-Dichloroethane- $d_{4}$, toluene- $d_{8}$ and $p$-bromofluorobenzene were used as surrogate standards.

\subsection{Analytical methods}

VOC concentrations were determined using modified US EPA methods 524.2 (Eichelberger et al., 1990; Kuo et al., 1996). A 25-ml water sample was collected after tap water was run for 5 min. Samples were stored at temperatures below $4^{\circ} \mathrm{C}$. Field and laboratory blanks were prepared to guarantee against contamination. A 5-ml water sample was injected into a purge-and-trap device (Tekma LSC 3000, Cincinnati, OH, USA) with a trap of Tenax/silica gel/charcoal. VOC levels were analyzed by gas chromatography-mass spectrometry (GC-MS Perkin Elmer Q-Mass 910, Norwalk, CT, USA). Ionization mode was $70 \mathrm{eV}$ with a scan mass range of 10-650 amu. The scan mass rate was $1 / \mathrm{s}$. A capillary column was used DB-5 $(30 \mathrm{~m} \times 0.25 \mathrm{~mm} \times 0.25 \mu \mathrm{m})$. The carrier gas used was helium. A carrier gas flow was set at $3.8 \mathrm{ml} / \mathrm{min}$ and the $\mathrm{GC}$ injection temperature was set at $200^{\circ} \mathrm{C}$. Initial temperature of the capillary column was set at $35^{\circ} \mathrm{C}$ and maintained for 3 min. The temperature increased at a rate of $4^{\circ} \mathrm{C} / \mathrm{min}$. The final temperature was set at $100^{\circ} \mathrm{C}$.

Quality control procedures were followed to ensure accuracy of results. Field duplicate samples were analyzed to make sure the relative difference was under $10 \%$. To prepare blank reagents, distilled water was boiled and passed through nitrogen gas for $1 \mathrm{~h}$. VOC concentrations 
in the blank reagent were then checked. A calibration curve with five different concentrations (from 2 to $25 \mu \mathrm{g} / \mathrm{l}$ ) was set up to measure VOC concentrations in water samples. Using a blank reagent, $15.63 \mu \mathrm{g} / 1$ was added and tested five times in order to arrive at the detection limits $[t .99(4) \times$ S.D. $=$ LOD $]$.

\section{Results}

Table 1 shows calibration curves and detection limits for the 21 VOC compounds. Overall, the correlation coefficient exceeded 0.99 . The lowest value was 0.9979 for 1,2-dichlorobenzene and highest was 0.9998 for dibromochloromethane. Except for trans-1,3-dichloropropene which wasn't detected, the range was from 0.02 to $1.48 \mu \mathrm{g} / \mathrm{l}$. For THM concentrations, chloroform was 0.36 $\mu \mathrm{g} / 1$, bromodichloromethane was $0.02 \mu \mathrm{g} / 1$, dibromochromomethane was $1.36 \mu \mathrm{g} / 1$ and bromoform was $0.10 \mu \mathrm{g} / 1$.

Table 2 examines VOC compounds found in tap water. Except for bromoform, detection rates were highest for chloroform, bromodichloromethane and dibromochloromethane. Average concentrations of THMs were different among the three areas with the highest in Kaohsiung and lowest in Taichung. Except for THM compounds, toluene and 1,2-dichloroethane concentrations and detection rates were higher than other VOCs. Again, Kaohsiung was highest and Taichung lowest. Significantly, highest concentrations of trichloroethane and 1,1,1-trichloroethane were found in Taichung. Highest concentrations of benzene were found in Taipei but benzene was not detected in Kaohsiung.

Table 3 focuses on the concentrations and detection rates from boiled water. Levels decreased significantly following boiling. Detection rate of chloroform was higher than $60 \%$ and its concentration was highest in Kaohsiung. THM concentrations ranged from 7.44 to $21.30 \mu \mathrm{g} / 1$. After boiling, the removal rate ranged from $61 \%$ to $82 \%$. However, the detection rates for toluene and 1,2-dichloroethane did not significantly decrease.

Table 1

Calibration curve and detection limits $(\mu \mathrm{g} / \mathrm{l})$ of VOCs

\begin{tabular}{llll}
\hline VOCs & Calibration curve & $R$ & Detection limit \\
\hline Chloroform & $y=-0.189+15.129 x$ & 0.9990 & 0.36 \\
Bromodichloromethane & $y=6.971+36.496 x$ & 0.9992 & 0.02 \\
Dibromochloromethane & $y=6.765+53.476 x$ & 0.9998 & 1.36 \\
Bromoform & $y=9.823+60.976 x$ & 0.9996 & 0.10 \\
Toluene & $y=3.832+31.545 x$ & 0.9989 & 0.04 \\
1,2-Dichloroethane & $y=5.631+46.923 x$ & 0.9997 & 0.50 \\
1,1,1-Trichloroethane & $y=3.500+54.810 x$ & 0.9994 & 0.30 \\
$1,1,2$-Trichloroethane & $y=6.425+88.496 x$ & 0.9997 & 0.68 \\
Tetrachloromethane & $y=-0.036+90.090 x$ & 0.9995 & 0.64 \\
Tetrachloroethene & $y=6.076+75.757 x$ & 0.9996 & 0.24 \\
1,1,2,2-Tetrachloroethane & $y=12.034+67.567 x$ & 0.9992 & 0.58 \\
Benzene & $y=6.539+41.153 x$ & 0.9995 & 0.32 \\
1,2 -Dichloropropane & $y=8.930+232.560 x$ & 0.9993 & 0.36 \\
Trichloroethylene & $y=14.970+80.000 x$ & 0.9993 & 0.06 \\
Ethylbenzene & $y=3.195+24.390 x$ & 0.9995 & 1.48 \\
Chlorobenzene & $y=6.144+44.843 x$ & 0.9993 & 0.80 \\
1,2 -Dichlorobenzene & $y=3.004+42.017 x$ & 0.9979 & 1.44 \\
1,3-Dichlorobenzene & $y=9.699+27.100 x$ & 0.9995 & 0.22 \\
1,4-Dichlorobenzene & $y=9.613+26.316 x$ & 0.9994 & ND \\
cis-1,3-Dichloropropene & $y=1.443+113.636 x$ & 0.9994 & 0.04 \\
trans-1,3-Dicloropropene & $y=9.391+217.390 x$ & 0.9986 & \\
\hline ND, nondetectable & & &
\end{tabular}

ND, nondetectable. 
Table 2

VOC concentrations and detection rates in the three metropolitan areas

\begin{tabular}{|c|c|c|c|c|c|c|c|}
\hline \multirow[t]{2}{*}{ VOCs } & \multirow[t]{2}{*}{ Area } & \multirow[t]{2}{*}{$n$} & \multirow{2}{*}{$\begin{array}{l}\text { Detection } \\
\text { rate }(\%)\end{array}$} & \multicolumn{4}{|c|}{ Concentration $(\mu \mathrm{g} / 1)$} \\
\hline & & & & Minimum & Maximum & Mean & S.D. \\
\hline \multirow[t]{3}{*}{ Chloroform } & 1 & 44 & $44(100.0)$ & 2.34 & 79.20 & 17.55 & 16.49 \\
\hline & 2 & 40 & $40(100.0)$ & 2.39 & 99.00 & 69.19 & 33.51 \\
\hline & 3 & 47 & $45(95.7)$ & ND & 92.20 & 18.83 & 26.82 \\
\hline \multirow[t]{3}{*}{ Bromodichloromethane } & 1 & 44 & $37(84.1)$ & $\mathrm{ND}$ & 25.06 & 13.77 & 6.63 \\
\hline & 2 & 40 & $39(97.5)$ & ND & 66.46 & 29.70 & 14.74 \\
\hline & 3 & 47 & $47(100.0)$ & 12.85 & 46.69 & 19.47 & 8.91 \\
\hline \multirow[t]{3}{*}{ Dibromochloromethane } & 1 & 44 & $22(50.0)$ & ND & 13.67 & 5.78 & 5.88 \\
\hline & 2 & 40 & $25(62.5)$ & ND & 73.21 & 14.22 & 14.59 \\
\hline & 3 & 47 & $39(83.0)$ & ND & 27.45 & 11.63 & 7.04 \\
\hline \multirow[t]{3}{*}{ Bromoform } & 1 & 44 & $2(4.5)$ & ND & 11.71 & 0.52 & 2.39 \\
\hline & 2 & 40 & $0(0.0)$ & ND & 0 & 0 & 0 \\
\hline & 3 & 47 & $0(0.0)$ & ND & 0 & 0 & 0 \\
\hline \multirow[t]{3}{*}{ THMs } & 1 & 44 & & 3.53 & 111.91 & 37.61 & 21.63 \\
\hline & 2 & 40 & & 11.06 & 191.13 & 104.12 & 38.67 \\
\hline & 3 & 47 & & 25.87 & 147.78 & 49.93 & 31.93 \\
\hline \multirow[t]{3}{*}{ Toluene } & 1 & 44 & $22(50.0)$ & ND & 57.03 & 4.00 & 9.41 \\
\hline & 2 & 40 & $24(60.0)$ & ND & 63.12 & 15.88 & 17.71 \\
\hline & 3 & 47 & $39(83.0)$ & ND & 38.16 & 6.20 & 8.98 \\
\hline \multirow[t]{3}{*}{ 1,2-Dichloroethane } & 1 & 44 & $12(27.3)$ & ND & 14.18 & 2.67 & 4.53 \\
\hline & 2 & 40 & $31(77.5)$ & ND & 81.90 & 6.73 & 12.51 \\
\hline & 3 & 47 & $19(40.4)$ & ND & 5.92 & 2.03 & 2.50 \\
\hline \multirow[t]{3}{*}{ Ethylbenzene } & 1 & 44 & $3(6.8)$ & ND & 0.19 & 0.01 & 0.04 \\
\hline & 2 & 40 & $1(2.5)$ & ND & 10.58 & 0.26 & 1.67 \\
\hline & 3 & 47 & $8(17.0)$ & ND & 11.05 & 0.71 & 2.63 \\
\hline \multirow[t]{3}{*}{ Trichloroethylene } & 1 & 44 & $24(54.5)$ & ND & 48.82 & 7.57 & 9.08 \\
\hline & 2 & 40 & $0(0.0)$ & ND & 0 & 0 & 0 \\
\hline & 3 & 47 & $1(2.1)$ & ND & 1.02 & 0.03 & 0.21 \\
\hline \multirow[t]{3}{*}{ 1,1,1-Trichloroethene } & 1 & 44 & $12(27.3)$ & $\mathrm{ND}$ & 5.29 & 0.69 & 1.26 \\
\hline & 2 & 40 & $1(2.5)$ & ND & 1.32 & 0.03 & 0.21 \\
\hline & 3 & 47 & $0(0.0)$ & ND & 0 & 0 & 0 \\
\hline \multirow[t]{3}{*}{ Benzene } & 1 & 44 & $4(9.1)$ & ND & 3.23 & 0.09 & 0.49 \\
\hline & 2 & 40 & $0(0.0)$ & ND & 0 & 0 & 0 \\
\hline & 3 & 47 & $8(17.0)$ & ND & 4.09 & 0.03 & 0.85 \\
\hline \multirow[t]{3}{*}{ trans-1,3-Dichloropropene } & 1 & 44 & $2(4.5)$ & ND & 11.14 & 0.48 & 2.24 \\
\hline & 2 & 40 & $1(2.5)$ & $\mathrm{ND}$ & 10.68 & 0.27 & 1.69 \\
\hline & 3 & 47 & $0(0.0)$ & ND & 0 & 0 & 0 \\
\hline \multirow[t]{3}{*}{$c i s-1,3$-dichloropropene } & 1 & 44 & $2(4.5)$ & ND & 3.91 & 0.18 & 0.82 \\
\hline & 2 & 40 & $0(0.0)$ & ND & 0 & 0 & 0 \\
\hline & 3 & 47 & $0(0.0)$ & ND & 0 & 0 & 0 \\
\hline
\end{tabular}

ND, non-detectable; 1, Taichung; 2, Kaohsiung; 3, Taipei. 
Table 3

VOC concentrations and detection rates after boiling in the three metropolitan areas

\begin{tabular}{|c|c|c|c|c|c|c|c|}
\hline \multirow[t]{2}{*}{ vOCs } & \multirow[t]{2}{*}{ Area } & \multirow[t]{2}{*}{$n$} & \multirow{2}{*}{$\begin{array}{l}\text { Detection } \\
\text { rate }(\%)\end{array}$} & \multicolumn{4}{|c|}{ Concentration $(\mu \mathrm{g} / \mathrm{l})$} \\
\hline & & & & Minimum & Maximum & Mean & S.D. \\
\hline \multirow[t]{3}{*}{ Chloroform } & 1 & 27 & $19(70.4)$ & ND & 13.44 & 3.86 & 3.49 \\
\hline & 2 & 17 & $11(64.7)$ & ND & 85.65 & 14.38 & 23.11 \\
\hline & 3 & 24 & $19(79.2)$ & ND & 97.12 & 7.07 & 19.39 \\
\hline \multirow[t]{3}{*}{ Bromodichloromethane } & 1 & 27 & $4(14.8)$ & ND & 15.86 & 2.01 & 4.93 \\
\hline & 2 & 17 & $4(23.5)$ & ND & 29.45 & 4.89 & 9.73 \\
\hline & 3 & 24 & $16(66.7)$ & ND & 17.12 & 8.93 & 6.51 \\
\hline \multirow[t]{3}{*}{ Dibromochloromethane } & 1 & 27 & $2(7.4)$ & ND & 16.58 & 1.02 & 3.74 \\
\hline & 2 & 17 & $2(11.8)$ & ND & 18.50 & 2.02 & 5.73 \\
\hline & 3 & 24 & $9(37.5)$ & ND & 11.55 & 3.66 & 5.20 \\
\hline \multirow[t]{3}{*}{ Bromoform } & 1 & 27 & $1(3.7)$ & ND & 15.02 & 0.56 & 2.89 \\
\hline & 2 & 17 & $0(0.0)$ & ND & 0 & 0 & 0 \\
\hline & 3 & 24 & $0(0.0)$ & ND & 0 & 0 & 0 \\
\hline \multirow[t]{3}{*}{ THM } & 1 & 27 & & ND & 52.07 & 7.44 & 11.00 \\
\hline & 2 & 17 & & ND & 133.60 & 21.30 & 37.23 \\
\hline & 3 & 24 & & ND & 97.12 & 19.66 & 20.05 \\
\hline \multirow[t]{3}{*}{ Toluene } & 1 & 27 & $13(48.1)$ & ND & 53.58 & 5.18 & 11.68 \\
\hline & 2 & 17 & $10(58.8)$ & ND & 61.11 & 13.66 & 16.67 \\
\hline & 3 & 24 & $16(66.7)$ & ND & 26.06 & 3.61 & 6.56 \\
\hline \multirow[t]{3}{*}{ 1,2-Dichloroethane } & 1 & 27 & $12(44.4)$ & ND & 11.01 & 3.78 & 4.44 \\
\hline & 2 & 17 & $10(58.8)$ & ND & 7.62 & 3.39 & 2.99 \\
\hline & 3 & 24 & $10(41.7)$ & ND & 5.82 & 2.05 & 2.49 \\
\hline \multirow[t]{3}{*}{ Ethylbenzene } & 1 & 27 & $1(3.7)$ & ND & 10.61 & 0.39 & 2.04 \\
\hline & 2 & 17 & $0(0.0)$ & ND & 0 & 0 & 0 \\
\hline & 3 & 24 & $2(8.3)$ & ND & 1.09 & 0.05 & 0.22 \\
\hline \multirow[t]{3}{*}{ Trichloroethylene } & 1 & 27 & $1(3.7)$ & ND & 15.14 & 0.56 & 2.91 \\
\hline & 2 & 17 & $0(0.0)$ & ND & 0 & 0 & 0 \\
\hline & 3 & 24 & $0(0.0)$ & ND & 0 & 0 & 0 \\
\hline \multirow[t]{3}{*}{ 1,1,1-Trichlornethene } & 1 & 27 & $2(7.4)$ & ND & 4.23 & 0.21 & 0.85 \\
\hline & 2 & 17 & $0(0.0)$ & ND & 0 & 0 & 0 \\
\hline & 3 & 24 & $0(0.0)$ & ND & 0 & 0 & 0 \\
\hline \multirow[t]{3}{*}{ Benzene } & 1 & 27 & $6(22.2)$ & ND & 3.75 & 0.21 & 0.73 \\
\hline & 2 & 17 & $1(5.9)$ & ND & 3.35 & 0.20 & 0.81 \\
\hline & 3 & 24 & $3(12.5)$ & ND & 1.09 & 0.13 & 0.35 \\
\hline
\end{tabular}

ND, non-detectable; 1, Taichung; 2, Kaohsiung; 3, Taipei.

\section{Discussion}

Several methods of pretreatment were used to measure VOC concentration in the water such as purge-and-trap, liquid-liquid extraction, static headspace technique and membrane process
(Brass, 1980). The purge-and-trap method is more popular because it can treat many samples simultaneously and has a favorable reproducibility. Many types of GC detectors were used such as Mass, ELCD, ECD and FID. US EPA Method 524.2 uses a mass detector to measure VOC concentration in drinking water and it is the 
recommended method for its qualitative and quantitative results. Olynyk et al. (1981) used a purge-and-trap device for pretreatment and a $\mathrm{GC} /$ Mass for measuring VOCs in drinking water. He used a packed column to measure VOC range from 18.8 to $20.2 \mu \mathrm{g} / \mathrm{l}$. Highest variations were found among 1,1,2,2-tetrachloroethane, toluene, chlorobenzene and ethylbenzene. The average for method efficiency was approx. 70\%. Bromoform and carbon tetrachloride were only $50 \%$. Viorica et al. (1987) compared results from VOC concentration in drinking water using pack and capillary columns. He found the capillary column's resolution and reproducibility were better than those of the pack column. The capillary column can also detect VOC concentrates 200 times lower than the pack column.

In the current study, the reproducibility ranged from $0.02 \%$ to $1.25 \%$. The purge efficiency was better than $90 \%$ for the 21 tested VOC compounds. All but dibromochloromethane (1.36), chlorobenzene (1.48) and 1,3-dichlorobenzene (1.44) had detection limits within the range specified by US EPA Method 524.2. Chaign (1992) used two kinds of detectors (FID, ECD) and found the latter to have a lower detection limit. In the current study, the mass detector's detection limit fell Chaing's results for the FID and ECD. Even though laboratory limitations did not permit compounds such as carbon tetrachloride, styrene, vinyl chloride and xylene to be measured, the analytical methods of the current study are reliable and reproducible. Although Taiwan (1995) has yet to publish standardized methods for measuring VOCs in drinking water or set permissible levels for VOC compounds, the authors have successfully established methods based on US EPA Method 524.2.

Results from drinking water showed significantly high concentrations of THMs. Overall, chloroform was highest, followed by bromodichloromethane, then dibromochloromethane. The THM with the lowest concentration was bromoform. This is due to the fact that bromide content is usually low in river and underground water. In 1992, because Bradawy (1992) used desalinated water as a water source, bromi- nated THMs were much higher than chloroform. THMs can be traced to chlorination except for THM by-products of chlorination such as dicholoroacetic acid, trichloroacetic acid, formaldehyde, choralhydrate, acetaldehyde, etc. THM concentrations can be affected by factors including the precursor, water source, their properties (such as $\mathrm{pH}$, total organic compound, temperature, bromide concentration) and how the water supply facility treats the water source. In Egypt, Hassan et al. (1996) found the THM range to be from 18.3 to $67.3 \mu \mathrm{g} / 1$ compared to $12.5-37.5 \mu \mathrm{g} / 1$ in Japan and $0.2-25 \mu \mathrm{g} / 1$ in Sweden. The mean value in Thailand was $44.9 \mu \mathrm{g} / 1$. Compared to these studies, THM concentrations were much higher in the current study (from 37.6 to 104.1 $\mu \mathrm{g} / 1)$. Reasons for this significant difference are most likely because samples were taken directly from households (not from water supply plants), treatment facilitics differ in tcrms of processes and chlorination, and a large percentage of Taiwanese residences use tanks for water storage which, if rarely cleaned, may result in high concentrations of precursors. Another possible reason for contamination of drinking water may be the fact PVC pipes are commonly used to transport water from the treatment plant to households (Larsen et al., 1983).

Today, in Taiwan, contamination of ground water by petroleum companies is a problem. In a 1987 Lockheed survey (Yang and Rauckman, 1987 ) in the United States, ground water samples were collected near 180 hazardous disposal sites in all 10 US EPA regions. Of the 28 compounds tested, trichloroethylene had a percent positive rate of $51.3 \%$ and xylenes with $42.6 \%$, and tetrachloroethylene with $36.0 \%$. Except for these three, other VOC compounds ranged from $5.5 \%$ to $33.4 \%$. Most VOCs had an average concentration exceeding the maximum contaminant level goal (MCLG). A 1995 Taiwan EPA report found that $5.7 \%$ of 4866 underground gasoline tanks were over 20 years old and $4 \%$ were between 10 and 20 years old. There have been several recent incidents of leaks from the gasoline tanks or pipes which has contaminated underground water. These incidents further show the urgency of the 
need for regular monitoring of VOC levels in household drinking water.

Because THMs are suspected carcinogens and/or mutagenic compounds, the US EPA recommends a maximum contamination level of 0.1 $\mathrm{mg} / \mathrm{l}$. The WHO recommends a permissible level for chloroform in drinking water of $30 \mu \mathrm{g} / 1$ (World Health Organization, 1984). However, average THM and chloroform levels in Kaohsiung greatly surpassed these recommended limits. Approximately $90 \%$ of surveyed households did not use tap water as a direct source of drinking water - most households bought mineral water or drank mountain water. Some residents mentioned during summer they could detect a chlorine odor coming from the tap water. The current study found that $61-82 \%$ of all THMs were removed following boiling. Epidemiological studies (Kool and Kreijl, 1984; Zoetman, 1985) indicate there is an increased risk of cancer due to organic contaminants associated with water chlorination. $\mathrm{Mu}$ tagenic activity can be removed by activated carbon and be reduced by dechlorinating agents. Boiling, however, cannot completely remove mutagenic activity, such as several carcinogenic chemicals including chlorinated acetic acids, haloacetonitrites and chlorinated phenols. Government programs have been established in Kaohsiung with a top priority of providing a better quality of water for its residents. The results from the current study can be used as a reference and baseline for the government in its overall goal of improving the quality of drinking water and one day allowing the people of Taiwan to drink tap water directly.

\section{Acknowledgements}

This study was supported by special grant from the National Science Council NSC85-2621-P039002 .

\section{References}

Attias L, Contu A, Loizzo A, Massiglia M, Valente P, Zapponi GA. Trihalomethanes in drinking water and cancer: a risk assessment and integrated evaluation of available data, in animals and humans. Sci Total Environ 1995;171:61-68.

Bradawy MI. Trihalomethane in drinking water supplies and reused water. Bull Environ Contam Toxicol 1992;48:157-162.

Brass HT. The analysis of trihalomethanes in drinking water by purge and trap and liquid-liquid extraction. Am Lab 1980; July:23 30.

Chaign CY. VOCs concentrations in water by purge and trap technique. Master thesis, National Tsing-Hua University, 1992.

Chiang TG. By-products of drinking water and treatment techniques in Taiwan area. Taiwan EPA 84-E3J1-0901, 1995.

Eichelberger JW, Bellar TA, Ponnelly JP, Budde WL. Determination of volatile organic in drinking water with EPA method 524.2 and ion trap detector. J Chromatogr 1990;128:461-467.

Hassan AAM, Benfenati E, Franell R. Detection and quantification of trihalomethanes in drinking water from Alexandria, Egypt. Bull Environ Contam Toxicol 1996;56:397-404.

Kool HJ, Kreijl CFV. Formation and removal of mutagenic activity during drinking water preparation. Water Res 1984;18:1011- 1016.

Kuo HW, Lo II, Chan CC, Lai JS, Wang JD. Volatile organic compounds in drinking water near petrochemical factories in Taiwan. Chemosphere 1996;33:913-920.

Larsen CD, Love TO, Reynolds G. Tetrachloroethylene leached from lined asbestos-cement pipe into drinking water. J Am Water Works Assoc 1983;75:184-188.

Morris RD, Audet AM, Arogelillo IF, Chalmers TC, Mosteller F. Chlorination, chlorination by products and cancer: a meta-analysis. Am J Publ Health 1992;82:955-963.

Olynyk P, Budde WL, Eichelberger JW. Simultaneous qualitative and quantitative analysis I. Precision of compounds amenable to the inert gas purge-and-trap method. J Chromatogr Sci 1981;19:377-382.

Taiwan EPA. Annual report of environmental protection in Taiwan. Taiwan, ROC: EPA, 1995.

Taiwan Water Supply Corporation. The statistical data and water quality. Taiwan, ROC: Water Supply Corporation, 1995.

Viorica LA, Richard W, Michael F, Richard S. Determination of volatile priority pollutants in water by purge and trap and capillary column gas chromatography/mass spectrometry. J Chromatogr Sci 1987;25:286-291.

World Health Organization (WHO). Guidelines for drinking water quality, vol 2. Gencva, Switzerland: WHO, 1984.

Yang RSH, Rauckman EJ. Toxicological studies of chemical mixtures of environmental concern at the National Toxicology Program health effects of groundwater contaminants. Toxicology 1987;47:15-34.

Zoetman BCJ. Drinking water and health hazards in environmental perspectives. Sci Total Environ 1985;47:487-503. 